\title{
Biological Characteristics of the Ginseng Stem Fungus Gnat (Phytosciara procera) and Its Environmental-friendly Control Using Modified Topping of Ginseng Peduncles
}

\author{
Seung-Hwan Lee ${ }^{1 *}$, Jung-Sup Shin', Tae-Gyun Hong', Young-Joon Ahn² and Dae-Hui Cho' \\ ${ }^{1}$ Institute of Technology, KGC R\&D Headquarter, Daejeon 305-345, Korea \\ ${ }^{2}$ Department of Agricultural Biotechnology, Seoul National University, Seoul 151-921, Korea \\ (Received December 31, 2009; Revised February 17, 2010; Accepted February 17, 2010)
}

\begin{abstract}
This study examined the biological characteristics of the insect and examined potential cultural controls using peduncle topping methods. Ginseng stem fungus gnat eggs hatched after 5 days; ecdysis lasted 3-4 weeks, and after 5 days pupation, adults emerged. Adults deposited eggs 1-2 days after emerging, and the entire life cycle lasted 32-40 days. The fungus gnats laid eggs $327 \times 220 \mu \mathrm{m}$ in size on cut planes of stems, but not on intact stem parts that had not been topped or wounded. Analyses of major weather data for the experimental areas and weather data for the past 30 years acquired from the Korea Meteorological Administration revealed that fungus gnat dispersion was prevalent under highly humid conditions and in areas with thick and frequent fogging. Among the topping times examined, fungus gnat damage to ginseng was lowest when topping occurred in late May. Among the five different topping methods evaluated on experimental ginseng farms, the cumulative fungus gnat damage to ginseng was low $(0.8 \%)$ under partial peduncle topping (removal of peduncle with lateral fruit remaining) and removal of only flower buds $(0.6 \%)$, with fungus gnat control effects of $82 \%$ and $86 \%$, respectively, compared to conventional topping (removal of peduncle about $5 \mathrm{~cm}$ above its base). No fungus gnat damage to ginseng was observed under the no-topping treatment. These results suggest that partial topping of peduncles, while letting lateral fruits remain, is a potentially environmentally friendly method of controlling the ginseng stem fungus gnat.
\end{abstract}

Key words : Phytosciara procera, ginseng stem fungus gnat, environmental-friendly control

\section{INTRODUCTION}

Ginseng (Panax ginseng C. A. Meyer) is a large income crop that is highly prized for its medicinal properties. Commercial markets of 6-year-old ginseng have been enlarged to provide raw materials for the production of red ginseng. In ginseng cultivation, especially that of 6year-old ginseng, the ginseng plants are exposed to various diseases and insect pests for a long period of time. Several fungi (Cylindrocarpon destructans) and the bacterial pathogens (Erwinia Pseudomonas, and Agrobacterium) are important causes of disease in ginseng [1-3]. Insect pests including four species of Lepidoptera, five species of Coleoptera, one species of Homoptera, three species of Orthoptera, and one species of Diptera are also known to cause ginseng damage [4]. Among these insect pests, the ginseng stem fungus gnat, Phytosciara procera,

* Corresponding author. E-mail: shlee74@kgc.or.kr

Phone: +82-42-870-3121, Fax: +82-42-870-3117 of the order Diptera, has been recently renamed based on detailed descriptions [5], although this insect was first observed to cause ginseng damage in Yongin in 1993 [4].

The stem fungus gnat deposits eggs on cut planes or other wound sites usually produced during the topping of ginseng peduncles, a method used for removing flower buds to prevent seed formation, thereby promoting the vegetative growth (root growth) of ginseng rather than reproductive development. Larvae of the ginseng stem fungus gnat, once hatched, damage internal ginseng tissues, which are then vulnerable to secondary infections of soft rot pathogens such as Erwinia carotovora subsp. carotovora, the causal agent of ginseng stem rot, rapidly enhancing the development of rot symptoms [5].

Insect pests are usually controlled using chemical pesticides, but the use of agrochemicals is limited in ginseng cultivation because of ginseng's widespread use as a health food. The larvae of the stem fungus gnat develop inside the peduncles or stems, which makes it difficult to 
detect the initial damage and even to control the insect using chemical pesticides after detection. Therefore, the goals of this study were to examine the growth, development, and reproduction of the ginseng stem fungus gnat in relation to environmental conditions and to identify a potentially environmentally friendly cultural control method by optimizing the timing and method of peduncle topping.

\section{MATERIALS AND METHODS}

\section{Life cycle of the ginseng stem fungus gnat on selected experimental farms}

Five- and 6-year-old ginseng fields in Yeongwol and Cheolwon, South Korea, respectively, were selected as experimental farms. Ginseng stem fungus gnats had been found in the fields in the previous year (2007) and larvae at the stage just before emergence were found on the basal stems of ginseng plants in April 2008. To study the fungus gnat life cycle, ginseng stems infested with fungus gnat larvae were collected from the experimental plots and placed in polyethylene containers incubated at $25 \pm$ $1^{\circ} \mathrm{C}$ and a relative humidity of $75 \pm 1 \%$ under 12 -h light and 12-h dark conditions.

\section{Oviposition characteristics of the ginseng stem fun- gus gnat}

Oviposition characteristics of the ginseng stem fungus gnat, including preferred egg-laying locations and times, were examined. To examine the effect of peduncle topping on oviposition, 10 adults were inoculated on ginseng stems or peduncles with or without cuts on one side, and eggs laid by the insects on the cut planes, wound sites, and surfaces of stems and peduncles were observed with the naked eye and under a compound light microscope (Optiphoto-2; Nikon, Tokyo, Japan). To examine the effect of peduncle topping at different peduncle growth stages on fungus gnat oviposition, samples of the lower, middle, and upper portions of peduncles were collected at 10-day intervals from early May through early June from three different ginseng varieties (Jakyeong, Cheonpoong, and Yeonpoong) grown in experimental ginseng fields at the KT\&G Central Research Institute in Suwon, South Korea. Hardness of the peduncle samples, which may have had an effect on stem fungus gnat oviposition, was measured using a Compac-100 rheometer (Sun Scientific Co., Ltd., Tokyo, Japan).

Relationships between seasonal dispersion of the ginseng stem fungus gnat and weather conditions

Seasonal dispersion of the ginseng stem fungus gnat was examined at the experimental ginseng farms in Yeongwol and Cheolwon, where ginseng was grown using double-clothed black polyethylene mats and shading sheets. Yellow sticky flat traps of $25 \times 15 \mathrm{~cm}$ (Green Agro Tech, Ltd., Kyungsan-Si, Kyungbuk, Korea) were established at the ginseng farms, and the number of adult fungus gnats attracted to the traps was examined at 10day intervals from late May to mid-September. The fungus gnat population collected on the yellow sticky traps was evaluated with respect to the growing season weather conditions (daily average temperature and rainfall) of the experimental areas using Korea Meteorological Administration (KMA) weather data. KMA data for the past 30 years, from 1978 to 2007, for areas that have experienced problems with the ginseng stem fungus gnat during that period ( 9 areas in total, including Yongin, the site of the fungus gnat's first occurrence) were also analyzed to determine if a relationship existed between fungus gnat dispersion and weather conditions.

Peduncle topping methods and the occurrence of ginseng damage by the ginseng stem fungus gnat

Five different topping methods were applied in the experimental ginseng farms at Cheolwon and Yeongwol to examine the effects of topping on the occurrence of fungus gnat damage on ginseng: conventional topping (removal of peduncle about $5 \mathrm{~cm}$ above its base), partial topping (removal of the peduncle with lateral fruit remaining), main fruit topping (removal of the main fruit with the rest of the peduncle remaining), complete topping (removal of the entire peduncle), and no topping (peduncle not removed) (Fig. 1). Toppings were performed starting in late May, and fungus gnat damage to ginseng was examined at 10-day intervals from early June to examine the potentials of the topping methods to control the ginseng stem fungus gnat.

\section{RESULTS AND DISCUSSION}

\section{Life cycle of the ginseng stem fungus gnat}

Ginseng stem fungus gnats collected from the affected ginseng fields were reared in vitro with ginseng stems as food to examine the insect's life cycle. It took 5 days for the larvae to hatch from the eggs. The larvae were a translucent white to light yellow in color. The larvae grew through ecdysis by feeding on ginseng stems and turned yellow just before pupating, with the larval stages from egg hatching to pupation taking 3-4 weeks (Fig. 2). Adult fungus gnats emerged from pupae after 5 days of pupation 

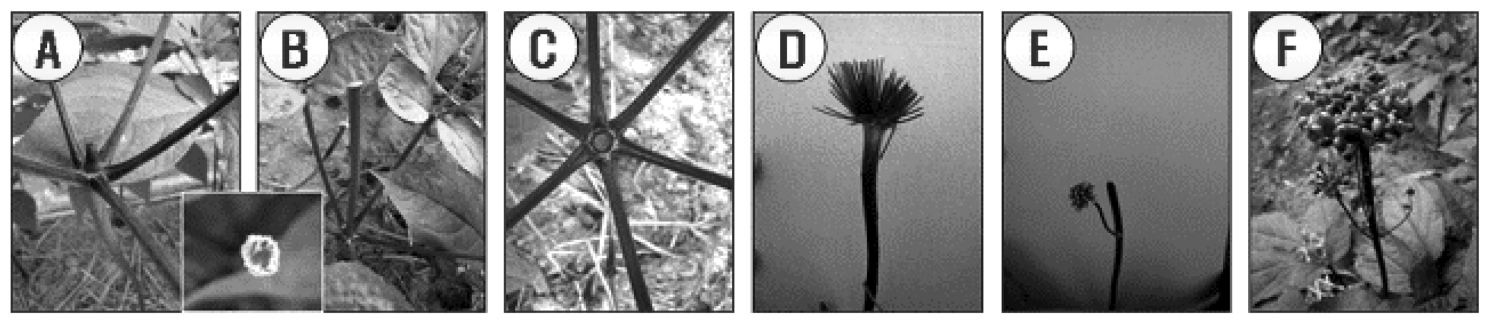

Fig. 1. The five methods of topping ginseng peduncles: conventional topping (removal of peduncle about $5 \mathrm{~cm}$ above its base) (A, B), complete topping (removal of the entire peduncle) (C), main fruit topping (removal of the main fruit with the rest of the peduncle remaining) (D), partial topping (removal of peduncle with lateral fruit remaining) (E), and no topping (no peduncle removal).

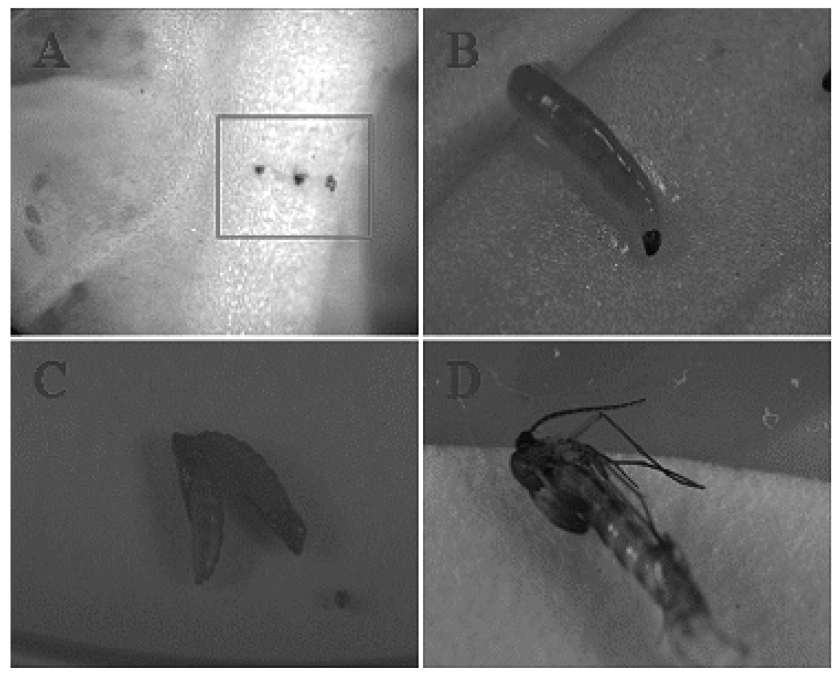

Fig. 2. Life cycle of the ginseng stem fungus gnat showing the morphologies of the larval pellicle (A), the larva (B), pupa (C), and emerged adult (D).

and deposited eggs 1-2 days later. In total, the life cycle of this insect lasted 32-40 days in this experiment.

\section{Oviposition and feeding characteristics}

Adult fungus gnats were placed in polyethylene containers with ginseng stems with or without peduncle topping to examine ovipositional characteristics (Fig. 3). Eggs were only laid on cut planes of the stems, not on intact stem parts. Eggs were $327 \times 220 \mu \mathrm{m}$ in size. At 34 days after hatching, the larvae were $655 \mu \mathrm{m}$ in length, with two pairs of chewing-type mouthparts at the head region, which they used for feeding and damaging peduncles and internal stem tissues.

Examination of the peduncles of the three ginseng varieties revealed that hardness levels were 3.2, 1.9, and 2.6 times higher in early June than in early May in varieties Jakyeong, Yeonpoong, and Cheonpoong, respectively. In early June, the hardness of the upper, middle, and lower parts of the peduncles was 401,456 , and $487 \mathrm{~kg} \mathrm{~cm}^{-2}$ in var. Jakyeong; 106, 278, and $397 \mathrm{~kg} \mathrm{~cm}^{-2}$ in var. Yeonpoong; and 262, 376, and $408 \mathrm{~kg} \mathrm{~cm}^{-2}$ in var. Cheonpoong, respectively, suggesting that the lower portions of the peduncles are more hardened than the upper portions in all three varieties (Fig. 4). However, we found no eggs on intact stems or peduncle surfaces, but only on cut

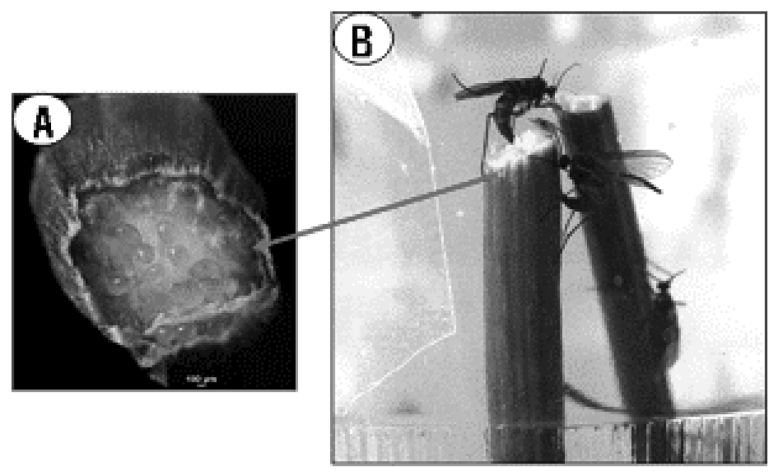

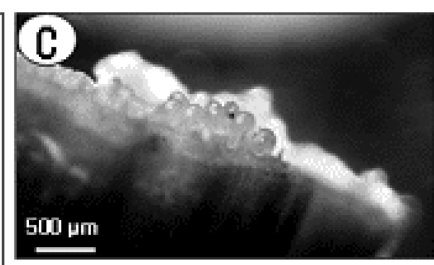

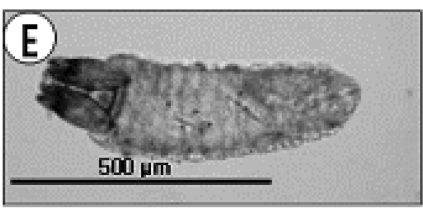

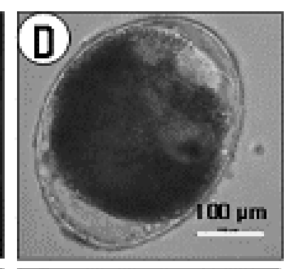

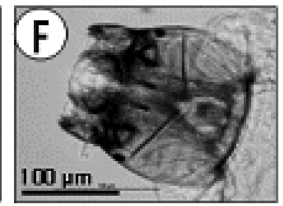

Fig. 3. Views of ginseng stem fungus gnat eggs deposited on cross-cutting (A, B) and longitudinal (C) planes of the peduncles; egg morphology, $327 \times 220 \mu \mathrm{m}$ in size (D); larval morphology at 3-4 days after hatching (emergence), $655 \mu \mathrm{m}$ in length; and larval caput (E). 

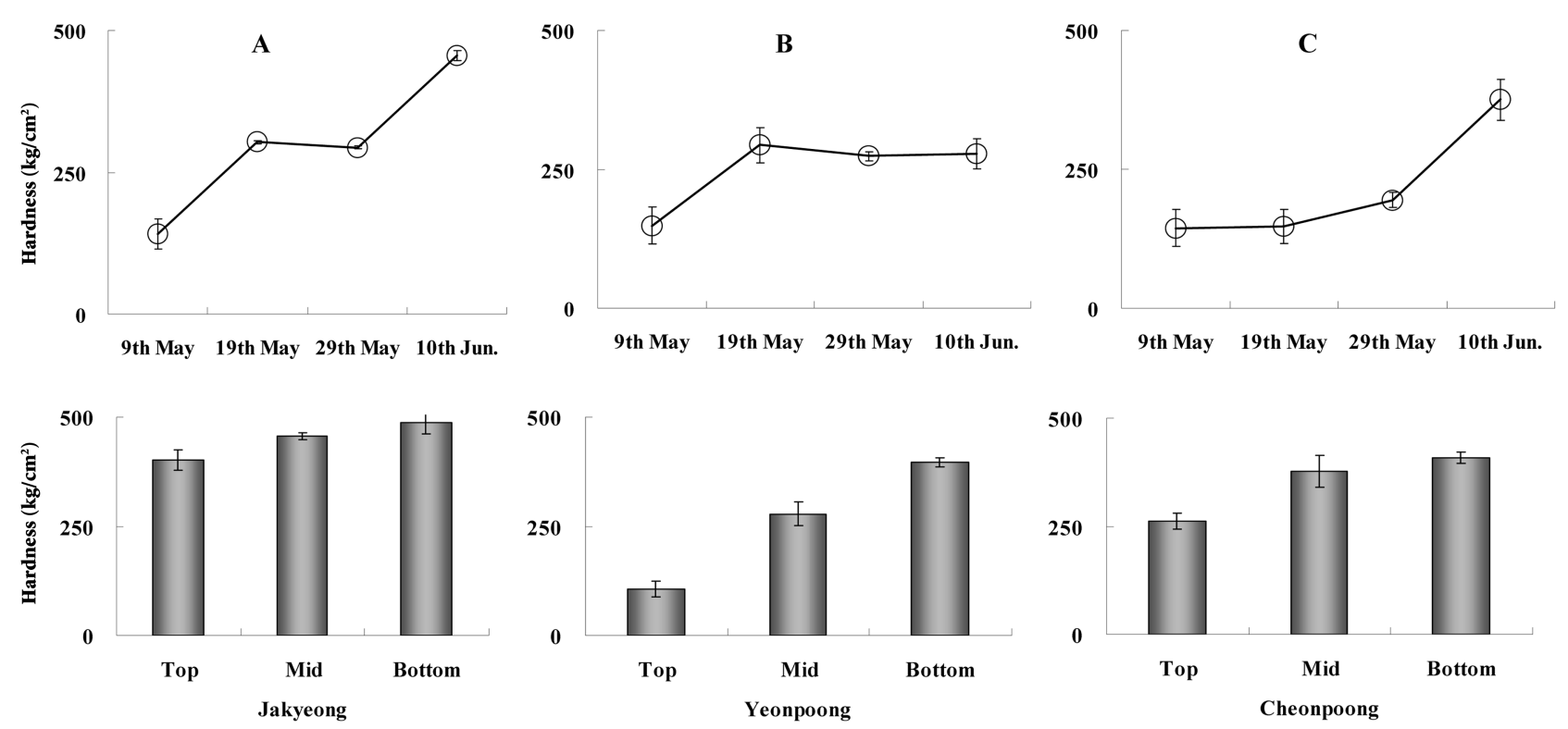

Fig. 4. Changes in the hardness of ginseng peduncles of the three ginseng varieties Jakyeong (A), Yeonpoong (B), and Cheonpoong (C), with peduncle growth stage (upper figures) and with peduncle section (top: upper portion, middle: middle portion, bottom: lower portion) (lower figures).

planes regardless of peduncle growth stage or position in all three ginseng varieties, indicating that adult fungus gnats cannot deposit eggs directly into intact ginseng stems or peduncles by piercing holes.

\section{Seasonal occurrence of the ginseng stem fungus gnat in relation to environmental conditions}

An average of one to six adult ginseng stem fungus gnats were continuously trapped on the yellow sticky traps in the two experimental ginseng fields, based on observations at 10-day intervals from late May through mid-September. Adult fungus gnat emergence increased in late July and late August to early September, when daily rainfall levels was high (Fig. 5), suggesting that the fungus gnat population may increase under conditions of high humid, resulting in increased levels of aboveground

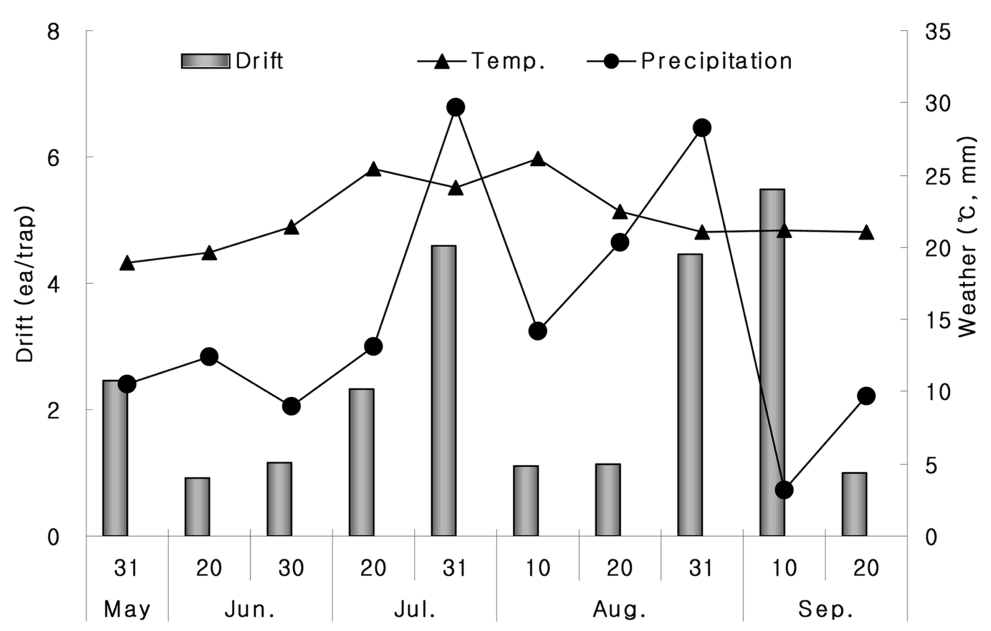

Fig. 5. Relationship between the dispersion (drift) of the ginseng stem fungus gnat during the growing season in ginseng fields (measured by the number of adult fungus gnats attracted to yellow sticky traps) and weather conditions (temperature and rainfall), based on weather data from the Korea Meteorological Administration. The numbers of fungus gnats collected on the sticky traps are averages of the numbers at 5-year-old (Yeongwol) and 6-year-old (Cheolwon) ginseng farms. 
damage to ginseng. Since fungus gnat damage was first observed in Yongin in 1993 [4], the fungus gnats have been found in various areas including Pocheon, Cheolwon, Hoengseong, Yeongwol, Jeongseon, Goesan, and Gongju; the average temperature in these areas has been $1-2^{\circ} \mathrm{C}$ lower and the continuous fogging period 1.5 times longer than nationwide averages (Table 1). These findings further support the results of our experiment that the occurrence of fungus gnat damage to ginseng is more prevalent in areas with high humidity and thick and frequent fogging.

\section{Cultural control of the ginseng stem fungus gnat}

The standard cultural method of ginseng published by the Rural Development Administration (RDA) suggests that peduncle topping to remove flower buds should be performed in early May to improve ginseng root development, cutting the peduncle $5 \mathrm{~cm}$ above its base. However, we observed that among the topping times examined from early May to early June, fungus gnat damage to ginseng was the lowest for the late May topping time (Fig. 6).

The partial peduncle topping method (which leaves lateral fruits in place) suggested by Shin et al. [5] was adopted and modified to examine the effect of topping methods on fungus gnat damage occurrence for the devel- opment of a cultural fungus gnat control that would not require chemical insecticide use. The cumulative fungus gnat damage to ginseng subjected to the complete topping of flower stalks was $15.7 \%, 3.5$ times more damage than that sustained under conventional topping (4.4\%), which removed all but the basal $5 \mathrm{~cm}$ of the peduncle. In contrast, the cumulative damage under partial peduncle topping (lateral fruits remaining) and the removal of flower buds only were low, $0.8 \%$ and $0.6 \%$, respectively, $82 \%$ and $86 \%$ less damage, respectively, than under conventional topping (Fig. 7). No fungus gnat damage was observed under conditions of no peduncle topping, confirming the above results that stem fungus gnats only occurred on ginseng stems and peduncles with cut planes and wounds. These results probably occurred because the withering of peduncles subjected to partial topping or the removal of flower buds alone was delayed long after topping, thus sustaining peduncle hardness (Fig. 8). Therefore, considering the benefit of topping to ginseng root development, partial topping that leaves lateral fruits in place would be more desirable for fungus gnat control than the removal of flower buds alone because in the latter case more peduncle remains behind, which would reduce the amount of nutrients available for vegetative (root) growth. The control rates of the 5- to 6-year-old

Table 1. Comparison of weather data for the areas with ginseng damage from the ginseng stem fungus gnat with nationwide data for the past 30 years from 1978 to 2007

\begin{tabular}{|c|c|c|c|c|c|c|c|}
\hline \multirow{2}{*}{ Area $^{1}$} & \multicolumn{4}{|c|}{ Temperature $\left({ }^{\circ} \mathrm{C}\right)$} & \multirow{2}{*}{$\begin{array}{c}\text { Yearly } \\
\text { precipitation } \\
(\mathrm{mm})\end{array}$} & \multirow{2}{*}{$\begin{array}{c}\text { Relative } \\
\text { humidity } \\
(\%)\end{array}$} & \multirow{2}{*}{$\begin{array}{l}\text { Continuous } \\
\text { fogging period } \\
\text { (hr) }\end{array}$} \\
\hline & Daily average & Daily highest & Daily lowest & Ground & & & \\
\hline Nationwide & $12.2 \pm 16.4$ & $17.8 \pm 1.35$ & $7.4 \pm 2.32$ & $14.4 \pm 1.57$ & $1302 \pm 178.2$ & $71 \pm 3.3$ & $126 \pm 82.7$ \\
\hline Damaged & $10.5 \pm 1.30$ & $16.5 \pm 1.33$ & $5.3 \pm 1.38$ & $12.4 \pm 1.23$ & $1286 \pm 37.4$ & $71 \pm 1.2$ & $197 \pm 57.4$ \\
\hline
\end{tabular}

${ }^{1)}$ Damaged areas include Yongin, Paju, Pocheon, Cheolwon, Hoengseong, Yeongwol, Jeongseon, Goesan, and Gongju

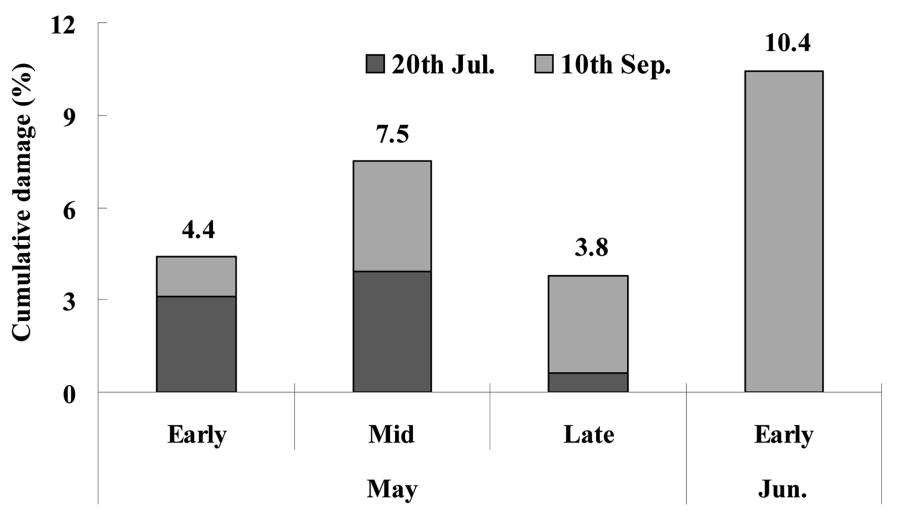

Fig. 6. Effect of peduncle topping time on the cumulative ginseng damage caused by the ginseng stem fungus gnat. Conventional topping (removal of peduncle about $5 \mathrm{~cm}$ above its base) was performed at 5-year-old (Yeongwol) and 6-year-old (Cheolwon) ginseng farms. 


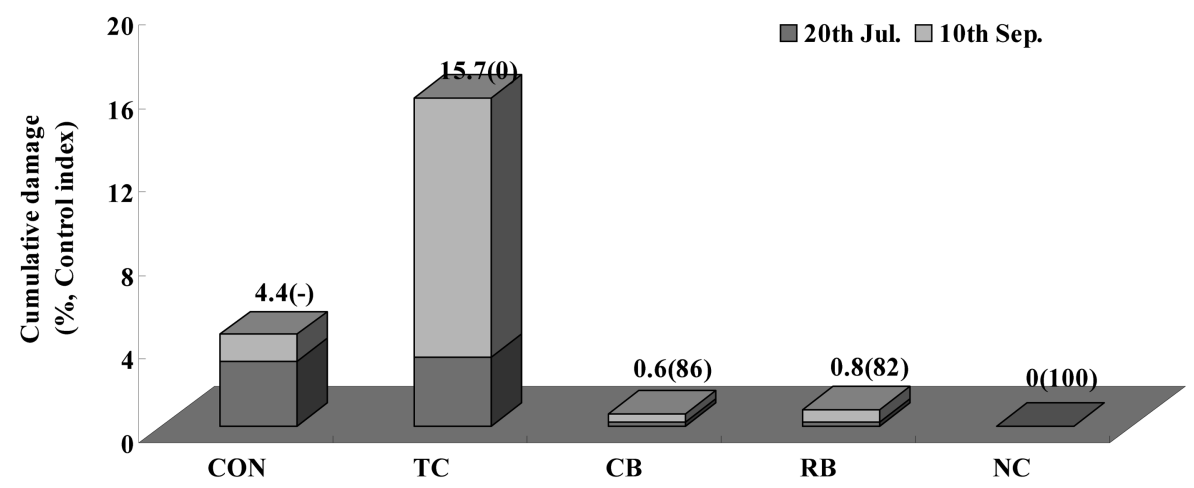

Fig. 7. Effects of the various peduncle topping methods on the cumulative ginseng damage caused by the ginseng stem fungus gnat, based on observations at 5-year-old (Yeongwol) and 6-year-old (Cheolwon) ginseng farms. CON: conventional topping, TC: complete topping, CB: main fruit topping, RB: partial topping (lateral fruit remaining), NC: no topping. Numbers in parentheses are reduction percentages (cultural control effect) relative to conventional topping.

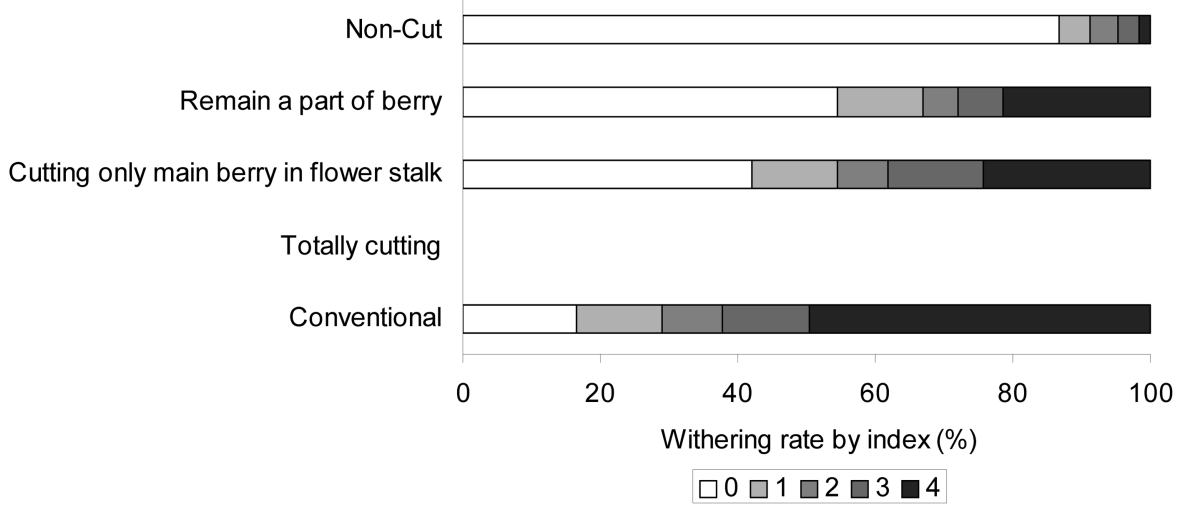

Fig. 8. Effects of the various ginseng peduncle topping methods on the withering of peduncles, based on observations at 5-year-old (Yeongwol) and 6-year-old (Cheolwon) ginseng farms from 3 June to 17 July 2008. Withering index: 0: no withering, 1: mild withering, 2: moderate withering, 3: heavy withering, and 4: complete peduncle withering.

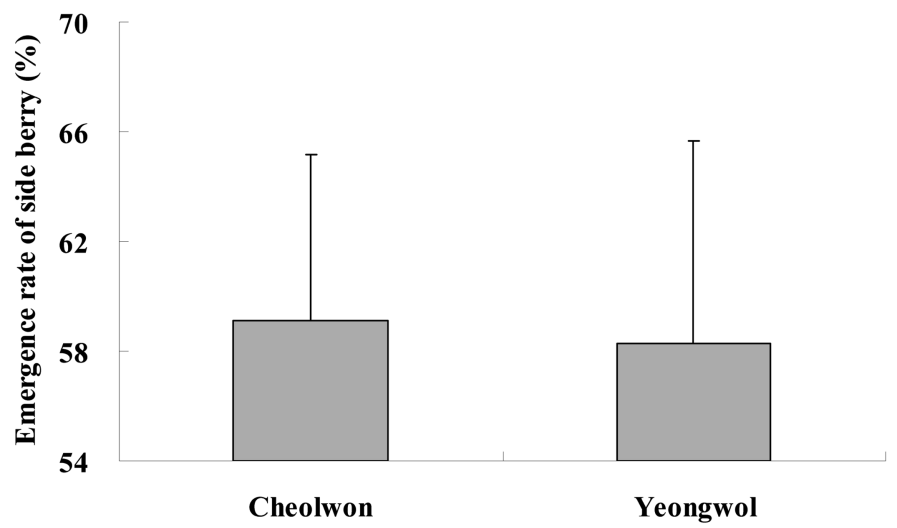

Fig. 9. Incidence of lateral fruit sprouting at 5-year-old (Yeongwol) and 6-year-old (Cheolwon) ginseng farms examined on 20 May 2008.

ginseng plants with lateral fruit formation were $59 \%$ and $58 \%$ at the Yeongwol and Cheolwon experimental farms, respectively (Fig. 9). For cultural control of the fungus gnat, partial topping of peduncles, while letting lateral fruits remain, seemed to be the best strategy to achieve decreased insect occurrence and ginseng damage. 


\section{REFERENCES}

1. Jeon YH, Park H, Lee BD, Yu YH, Chang SP, Kim SG, Hwnag I, Kim YH. First description of crown gall disease on ginseng. Plant Pathol J. 24: 207-210 (2008)

2. $\mathrm{Yu} \mathrm{YH}, \mathrm{Ohh} \mathrm{SH}$. Research on ginseng diseases in Korea. Korean J Ginseng Sci. 17: 61-68 (1993)

3. Yu YH, Yi, YK, Ohh SH. Stem rot of ginseng caused by
Erwinia carotovora subsp. carotovora. Korean J Plant Pathol. 7: 183-187 (1991)

4. Kim KW. Surveys on ginseng damage by insect and other animal pests. Korean J Appl Entomol. 33: 237-241 (1994)

5. Shin JS, Cho DH, Cho HS, Kim HY, Lee HS. A report on the damage caused by Phytosciara procera, ginseng stem fungus gnat. J Ginseng Res. 32: 275-278 (2008) 